\title{
Uses and Gratifications of News among Ethnic Groups in Nigeria \\ Ibrahim G. Saleeman
}

\author{
Ph.d Student of Communication, School of Multi-Media Technology and Communication, \\ College of Arts and Sciences, Universiti Utara Malaysia, Kedah \\ Email: rugmaak@yahoo.com
}

Adrian M. Budiman

Senior Lecturer, School of Multi-Media Technology and Communication, College of Arts and Sciences, Universiti Utara Malaysia, Kedah

Email: adrian@uum.edu.my

\section{Mohd Khairie Ahmad}

Senior Lecturer, School of Multi-Media Technology and Communication, College of Arts and Sciences, Universiti Utara Malaysia, Kedah

Email: khairie@uum.edu.my

\section{Doi:10.5901/mjss.2015.v6n3s1p178}

\begin{abstract}
Uses and Gratifications (U\&G) theory has enjoyed substantial usage for news study among media scholars . Previous studies have also explored news consumption among ethnic groups through the uses and gratifications approach. However, most of this effort has focussed on inter-national ethnic groups with little attention on intra-ethnic settings. This study examines the influence of ethnic identity on news motives among the three major ethnic groups in Nigeria.. We also examine the relationship between ethnic identity and gender as predictors of news usage. Survey questionnaires were administered on 400 undergraduates in three universities in Nigeria between January and April, 2014. We use Partial Least Square Structural Equation Modelling (PLS-SEM) approach to measure the relationships among the variables. Findings show that there is a significant difference among the ethnic groups in news usage
\end{abstract}

Keywords: news, gratifications, ethnicity, ethnic identity, motivations, intra-national, gender, PLS-SEM

\section{Introduction}

The fact that all contexts of communication can be approached through the understanding of uses and gratification (Rubin and Rubin, 1985) points to the intrinsic value of the Uses and Gratifications theory in identifying communication patterns of any social concept. It is no wonder that over the last 60 years, the theory has been used to study the public's perception of gratifications sought and obtained via engagement in mass communications across a variety of modalities such as television programs, phone usage, and print media (Thapa, 2002).

Demographic variables like gender and ethnic identity, among others, have been identified as predictors of media uses and gratifications.. Raacke and Bonds-Raacke (2008) examined the uses and gratifications of friend-networking sites among Hispanic, Caucasian, African and Native American college students. Thapa (2002) used the uses and gratifications theory to examine the recreational information needs and search behaviour of minority ethnic groups in America. Thapa had observed that Uses and Gratifications (theory) had scarcely been used to examine pattern of media use among ethnic groups, noting that theories of Mass Communication should be incorporated into research on interdisciplinary concepts of which ethnicity is one.

News consumption is a popular subject in Mass Communication research (see Micheistein \& Boczkowski, 2010; Livingstone \& Markam, 2008; Nguyen \& Western, 2007).. This is not unconnected with the several social values of news. News is one of the basic components of human interaction in any society. Social interaction and the entire public affairs mostly derive their orientation from the circulation of news. Because news is a form of knowledge which people seek for practical and psychological purposes (Hamilton, 2003), news consumption has become a cognitive, emotional, attitudinal and behavioural social phenomenon (McCombs, Holber, Kiousis \& Wanta, 2011). News has a cultural value serving as a 
source of norms, attitude and knowledge to successive generation of individuals in various societies (Gillespie, 1995, Johnson-Cartee, 2005). Moreover, news is one of the factors that help to shape different ideologies, identities and experiences (Cotter, 2010; Gandy, 1998; Hall, Antem \& Cakim, 1999). In fact, in the modern society, news is becoming increasingly more important to people in their daily lives. Globalisation and technological advancement in a paradoxical world filled with conflict is making people more conscious of time which in turn makes them more dependent on news for their daily lives (Johnson-Cartee, 2005).

Ethnicity in the context of news consumption has also been a relatively popular area of research in uses and gratifications. Findings of these studies have largely indicated that ethnicity influences news consumption behaviour. Wei (2008) found non- Whites to use the mobile phone for news more than the Whites in the United States; Albarran and Humphrey (1993) had also found significant difference in the TV news gratifications of Blacks and Hispanics in the United State; Gezduci and d'Haenens (2007) found ethnicity one of the strongest determinants of news usage among Turkish nationals in Belgium

\section{Statement of the Problem}

Ethnicity is a big issue in Nigeria, determining how and why Nigerians behave in almost all strata of the Nigerian society (John, Mohammed, Pinto \& Nkanta, 2007, Osaghae \& Suberu, 2005; Salawu, 2010). And given the socio-cultural importance of news (Hamilton, 2003; Johnson-Cartee, 2005; McCombs, Holber, Kiousis \& Wanta, 2011), this study intends to find out whether ethnic identities of Nigerians also influence their news usage

One of the most prominent theoretical approaches to the study of media usage is the Uses and Gratifications (U\&G) approach. For over 60 years, U\&G theory has been used to assess what motivations people derive from using the media (Thapa, 2002). Many empirical studies have used this approach to explore how and why people consume news (Althaus and Tewksbury, 2000; Cownberge, 2010; Palmgreen, Rubin and Weiner, 1980; Ghorui, 2012). More particularly, U\&G theory has been used to examine the influence of ethnic identity on news consumption (Gezduci \& d'Haenens, 2010; Wei, 2008). Most of these ethnicity-centered news consumption studies have focused on inter-national ethnic settings. Little attention has been given to intra-ethnic ethnic settings. This study will examine the influence of ethnic identity on news usage among three major ethnic groups in Nigeria.

Besides, studies of news usage among ethnic groups have examined mainly the news gratifications sought by the ethnic groups. Little attempt has been made to explore the extent to which each ethnic group obtains the news gratifications it seeks. Yet, there is an absolute discrepancy between media gratifications that are sought and the media gratifications that are eventually obtained or perceived to be obtained by media users (Durall, 1982; Katz, Blumler \& Gurentich, 1974; Palmgreen \& Rayburn, 1979). This study also explores the correlation between the news gratifications that are sought and the news gratifications obtained by each of the ethnic groups

This study is also examining the influence of gender on news usage with a view to comparing the relative predictive relevance of ethnic identity and gender on news gratifications sought. This is in view of the fact that the predictive value of ethnic-cultural variables has been assessed in isolation as opposed to in competition with sociodemographic characteristics (Gezduci \& d'Haenens, 2010, p 334). Previous studies that have taken up this challenge concentrate on inter-national ethnic settings ((Gezduci \& d'Haenens, 2010)

From the theoretical gap identified above, we sought to answer these research questions:

$R Q 1$ Does ethnic identity influence news gratifications sought among the Hausa- Fulani, Ibo and Yoruba ethnic groups in Nigeria?

$R Q 2$ Is there a significant difference in the news gratifications sought among the Hausa- Fulani, Ibo and Yoruba ethnic groups in Nigeria?

$R Q 3$ Does gender influence news gratifications sought among the Hausa- Fulani, Ibo and Yoruba ethnic groups in Nigeria

$R Q 4$ What is the relative predictive relevance of ethnic identity and gender on news gratifications sought (NGS) among the Hausa- Fulani, Ibo and Yoruba ethnic groups in Nigeria?

$R Q 5$ Is there a significant difference in the media used to obtain news gratifications among the Hausa- Fulani, Ibo and Yoruba ethnic groups in Nigeria?

$R Q 6$ Is there a correlation between the news gratifications sought and the news gratifications obtained of each of the Hausa- Fulani, Ibo and Yoruba ethnic groups in Nigeria? 


\section{Research Model}

Media uses and gratifications is all about the media consumers being in control of the communication process. This is because he/she goes into the communication process with certain social and psychological needs which determine where and how he/she gratifies those needs with respect to the media and their contents. The basic tenet of uses and gratifications is that certain personal, interpersonal and social needs determine how and why people select media which invariably means that media needs are influenced by personal and social identities ((Katz, Blumler \& Guventich, 1974; Rosengreen, Wenner \& Palmgreen, 1985). Such personal identities as age, gender, marital status, socio-economic status and ethnic identity have evolved as variables of media gratifications over the years (Emeanyonu, 1985; Ruggiero, 2000; Lee, Goh \& Chua, 2010;;).

Many gratification measures have been developed over the years but all of them seem to revolve around the five traditional typologies of Katz, Guventich and Haas (1974) which include cognitive needs (for information, knowledge and understanding of the environment), affective needs (for aesthetic, pleasure and emotional experiences), personal integrative needs (for credibility, confidence, stability and personal status), social integrative needs (for contact with friends, family and the world) and escapist needs (for escape, diversion and tension release). When these needs underlie the expectations of media consumers, they are labelled Gratifications sought (GS) (Johnson \& Yang, 2009).

Among the social variables that have empirically been found to influence GS for the news genre is ethnic identity. In two separate studies, Gerzduci and d'Haenens $(2007,2010)$ found significance difference in the news gratifications sought among ethnically diverse groups in Belgium. Albarran and Humphrey (1993) also found significant difference in the TV news gratifications of Blacks and Hispanics in the United States. Given these findings, this study hypothesises thus:

$\mathrm{H}_{1}$ Ethnic identity will positively influence news gratifications sought among Hausa-Fulani, Yoruba and Ibo ethnic groups in Nigeria

$\mathrm{H}_{2}$ There is a significant difference in the news gratifications sought by Hausa-Fulani, Yoruba and Ibo ethnic groups in their ethnic origins.

Gender difference has been found to predict news usage. In a study on the gratifications sought by the Chinese from watching television news, Nangog (2011) discovered a significant difference in the preferred TV news programs between males and females. Swamy (1997) had found gender to be a predictor of media preference for news. Men use online media for news than women while women were found to use newspapers for news than men. Wei (2008) also found a significant difference in the usage of mobile phones for news between males and females. In Glynn, Huge and Hoffman (2012), gender was found to significantly influence how Facebook is used for news. This is the basis of hypothesis three:

$\mathrm{H}_{3}$ Gender will influence NGS among Hausa-Fulani, Yoruba and Ibo ethnic groups in their ethnic origins

There is yet an empirical clarity on which of the ethnic identity and gender has more predictive relevance on news usage. Even in Gerzduci and d'Haenens (2010), where there is a recommendation for empirical assessment of 'competition' bewtween ethnic-cultural variables and socio-demographic characteristics in their predictive value on media usage, the competition between gender and ethnic identity is not clearly examined. However, because gender tends to exert more influence on other human activities than ethnic identity (see Eccles, 2005), we hypothesise that

$\mathrm{H}_{4}$ Gender will have more predictive value on NGS than ethnic identity

Studies that have explored the relationship between news gratifications sought and news gratifications obtained by ethnic groups are rare. However, other studies have found positive correlation between the gratifications sought and gratifications obtained by news consumers. Palmgreen et al (1980) investigated how gratifications sought (GS) from television news are obtained from network evening news programs and found each GS correlated in varying degree with its corresponding GO. Similarly, in his examination of the role of gratifications sought (GS) and gratifications obtained (GO) in predicting dependency on network evening news programs and 60 Minutes, Weinner (1982) found GS to be most strongly correlated to corresponding GO On the other hand, Dimmick et al (2004) found news in the internet to provide satisfaction to the news consumers.

Although studies that have directly examined the correlation between news gratifications sought and obtained in Nigeria are yet to be found, inference from findings of related studies could indicate a positive correlation. For example, in his analysis of the pattern of media use among Nigeria teachers, Ozor (1991) found most of the teachers using the media for various gratifications always. This inference is strengthened by the fact that when people do not get expected satisfaction from a particular media, they are more likely to change media (Yang, 2009). This is the basis of this study's seventh hypothesis:

$\mathrm{H}_{5}$ Gratifications sought (GS) for using news by each of the Hausa-Fulani, 
Yoruba and Ibo will positively correlate with Gratifications obtained (GO) by each of them.

Since the relatively wide diffusion of online media started at the onset of the $21^{\text {st }}$ century, global theoretical debate has persisted on the relationship between the new media and the conventional, traditional media as news outlets. The question is whether the online media have completely displaced the conventional media as news sources or it still remains a matter of one complementing the other. Due to this unclear pattern of relationship, some scholars have suggested a theoretical approach that can address usage of media for news consumption within the context of social practices. This probably explains why some scholars have found the use of uses and gratifications more appropriate because it is the motive that drives media choice for news consumption and not the media types (Dutta-Bergman, 2004). In other words, consumers are disinterested about the medium. Wherever their news needs can be gratified, they go for it. This position is buttressed by Dutta-Bergman's findings that in the United States, those who followed sports news in the new media complement that by also looking for sports news in the old media. The implication of this is the possibility that a particular news gratification can be sought in both the online and offline media. Or that different news gratifications by different media users can be sought and obtained in a particular media. This is the basis of the study's sixth hypothesis:

$\mathrm{H}_{6}$ There is no significant difference in the media used for news gratifications by Hausa -Fulani, Yoruba and Ibo ethnic groups in Nigeria.

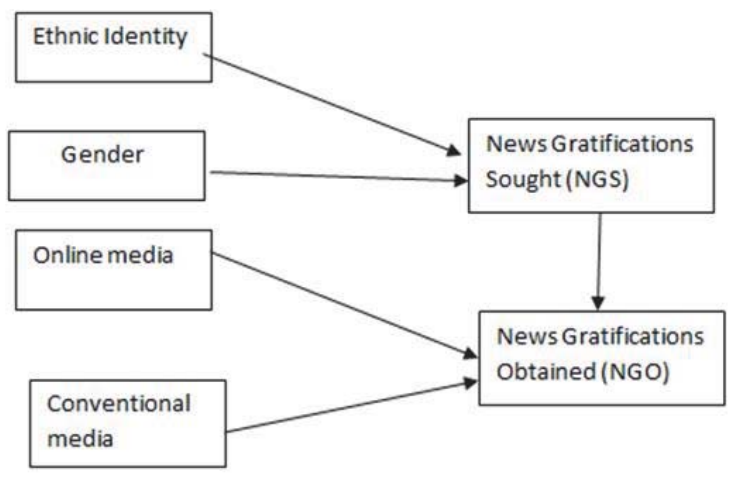

Fig. 1 The research model

\section{Method}

\subsection{Measures}

Between January and April, 2014, survey questionnaires were administered on 400 undergraduate students in three federal Nigerian universities. Through a random sampling, one federal university from each of the three geographical zones of the three ethnic groups under study was selected. Stratified samples of 108 Hausa-Fulani, 181 lbo and 111 Yoruba were then drawn from the total population of each of the ethnic groups in each of the three sampled universities through a proportionate sampling technique.

Based on the criteria of Hair et al (2014), 43 cases were excluded from the analysis leaving a total of 357. In some of these dropped cases, all the questions in a particular construct are left unanswered while in other cases, a considerable portion of the entire observation was not addressed by the respondent. Using both the boxplots and the percentiles techniques in SPSS, 33 more cases were excluded from the analysis for containing outlying responses. A total of 310 cases were therefore used for the analysis.

\subsection{PLS Estimation Results with smartPLS}

Partial Least Square-Structural Equation Modelling (PLS-SEM) was used to analyse the measurement and structural models of this study. The analyses were done on the smart- PLS 2.0 software. PLS-SEM was chosen mainly because of its non-requirement of normal data distribution. More so, the concern of this study is mainly the endogenous construct (NGS) which requires a variance-based method like PLS-SEM. 


\subsection{Measurement Model Assessment}

The six constructs (ethnic identity, gender, online media, conventional media, NGO and NGS) met the PLS-SEM threshold of internal consistency reliability and discriminant validity. NGS, NGO, online media and conventional media all have composite reliability above the 0.78 threshold while their Average Variance Extracted (AVE) also meets the 0.5 requirement. All the individual indicators of online media, conventional media, NGO and NGS constructs that are below .05 were deleted until the AVE criterion of 0.5 is met. Ethnic identity and gender are categorical, single item constructs.

Table 3.1 Reliability and validity scores

\begin{tabular}{ccccccc}
\hline & AVE & Composite Reliability & R Square & Cronbachs Alpha & Communality & Redundancy \\
\hline Conv med & 0.5595 & 0.7889 & & 0.6111 & 0.5595 & \\
NGO & 0.5135 & 0.8377 & 0.4139 & 0.7555 & 0.5135 & 0.0005 \\
Online med & 0.5181 & 0.783 & & 0.5361 & 0.5181 & 0.0007 \\
NGS & 0.5383 & 0.8525 & 0.3214 & 0.7821 & 0.5383 & 0.007 \\
\hline
\end{tabular}

\subsection{Structural Model Assessment}

The path relationships between the two exogenous variables (ethnic identity and gender) and the endogenous variable (NGS) were examined through the PLS-SEM algorithm and bootstrapping. The results show that ethnic identity positively relates with NGS with path coefficients of 0.07 and 0.115 for ethnic identity and gender respectively. However,after bootstrap samples of 5000 was run, ethnic identity's path coefficient of 0.07 is not statistically significant with a t value of 0.132). For PLS-SEM, the threshold for a critical $\mathbf{t}$ values using two-tailed test can be significant at either $10 \%(1.65), 5 \%$ (1.96), or $1 \%$ (2.57) (Hair et al., 2014). Correlation between NGS and NGO for ethnic identity as a construct is positively statistically significant with a t value of 14.563. But in order to test the hypothesis that there is a correlation between NGS and NGO of each of the ethnic groups, we ran PLS algorithm for each of the three ethnic groups after separating their data. A bootstrap sample of 5000 was run for each data. Results show that NGS and NGO positively correlate for each of the ethnic groups with significant t values of $6.910,7.744$ and 8.644 for Yoruba, Hausa nad Ibo ethnic groups respectively.. These results support our hypothesis five (H5). These results of path relationships are shown in table 3.2

The predictive relevance $\left(\mathrm{Q}^{2}\right)$ of ethnic identity and gender was assessed using the blindfolding window on the smartPLS to know their relative predictive values on NGS. To measure the predictive value of each of the exogenous constructs (ethnic identity and gender) on the endogenous construct (NGS), PLS path model was estimated twice to know the values of the endogenous construct when a particular exogenous construct is included and removed from the model. Both ethnic identity and gender have small predictive value, though that of gender is higher $\left(\mathrm{Q}^{2}=0.13\right)$. than that of ethnic identity $\left(Q^{2}=0.03\right)$. These results, which are shown in table 3.3 , support our hypothesis four $(\mathrm{H} 4)$.

Table 3.2. Results of Significant Relationships

\begin{tabular}{ccccc}
\hline Path Relationship & Std Beta & SE & t-Value & Decision \\
\hline Ethnic identity $>$ NGS & 0.007 & 0.0504 & 0.132 & Not Significant \\
Gender $->$ NGS & 0.115 & 0.0509 & $2.254^{* * *}$ & Significant \\
NGS $>$ NGO (Yoruba) & 0.617 & 0.0825 & $7.472^{* * *}$ & Significant \\
NGS $>$ NGO (Hausa) & 0.6175 & 0.0805 & $7.666^{* * *}$ & Significant \\
NGS -> NGO (lbo) & 0.6129 & 0.0772 & $7.939^{* * *}$ & Significant \\
\hline
\end{tabular}

Table 3.3. Effect Sizes- $f^{2}$ and Effect Size- $q^{2}$ on NGS

\begin{tabular}{cccc}
\hline & Path & $\mathrm{f}^{2}$ & $\mathrm{q}^{2}$ \\
Ethnic identity & 0.007 & 0.02 & 0.03 \\
Gender & 0.115 & 0.016 & 0.13 \\
\hline
\end{tabular}

\subsection{MGA results}

To determine if there is difference in the NGS and in the use of the media of the three ethnic groups, we performed the PLS non-parametric multi group analysis of PLS-SEM (Sarstedt, Henseler, \& Ringle, 2011). To measure each difference (difference in the NGS and in the use of the media of the three ethnic groups), we transferred the mean samples of path 
coefficients of each pair of the three ethnic groups into the Henseler excel template which automatically generates both the $t$ difference and the $p$-value for each pair. The sample means were generated by separately running the PLS algorithm for the path model of each of the ethnic groups after which 5,000 bootstrap samples were run for each using the Individual changes option on the bootstrapping window of the smartPLS. Since we are doing MGA involving more than two groups, Bonferoni tests were conducted to ensure there was no pair familywise error. Before bootstrapping, we assessed the measurement model of each of the ethnic groups to ensure that the thresholds of AVE and composite reliability of the items are attained. Results indicate there is a significant difference between the NGS of Hausa-Fulani and that of Ibo ( $p$-value $=0.02$ ) and between the NGS of Ibo and Yoruba ( $p$-value $=0.05)$. There is no significant difference in the NGS of Hausa-Fulani and that of Yoruba (p-value = 0.51). These results, which are shown in tables 3.4, 3.5 and 3.6, support our hypothesis two (H2). Although the path relationship between ethnic identity and NGS is not statistically significant, this result showing significant difference among the ethnic groups is an indication that ethnic identity does influence NGS in some measure. This conclusion is reinforced by the fact that ethnic identity has a predictive value on NGS, although with a small effect size (q2 $=0.03$ ). Our hypothesis one $(\mathrm{H} 1)$ can therefore be said to be partially supported

There is no significant difference among the three ethnic groups in their usage of each of the two media types to obtain news gratifications For online media and conventional media, there is no significant difference between HausaFulani and Ibo with $p$-values of 0.51 and 0.50 respectively. Between Yoruba and Ibo, the $p$-values are 0.49 and 0.20 for online media and conventional media respectively. And between Hausa-Fulani and Yoruba, the p-values are 0.49 and 0.49 respectively. These results which are shown in tables $3.7,3.8$ and 3.9 support hypothesis three $(\mathrm{H} 3)$

Table 3.4. Ethnic groups' difference on NGS (Yoruba vs. Hausa)

\begin{tabular}{cccc}
\hline Group 1: (Yoruba) & Group 3: (Hausa) & & \\
\hline$\theta^{(1)}$ & $\theta^{(2)}$ & Group Difference & P-Value \\
-0.0647 & -0.0726 & 0.199400 & 0.514000 \\
\hline
\end{tabular}

Table 3.5. Ethnic groups' difference on NGS (Yoruba vs. Ibo)

\begin{tabular}{rrrr}
\hline Group 1: (Yoruba) & Group 3: (lbo) & & \\
\hline$\theta^{(1)}$ & $\theta^{(2)}$ & Group Difference & P-Value \\
-0.0647 & 0.1347 & 0.007900 & 0.054600 \\
\hline
\end{tabular}

Table 3.6. Ethnic groups' difference on NGS (Hausa vs. Ibo)

\begin{tabular}{cccc}
\hline Group 1: ( Hausa) & Group 3: (lbo) & & \\
\hline$\theta^{(1)}$ & $\theta^{(2)}$ & Group Difference & P-Value \\
-0.0726 & 0.1347 & 0.207300 & 0.022700 \\
\hline
\end{tabular}

Note: $\theta(1)$ and $\theta(2)$ are the parameter estimate (path coefficients) of Group 1 and Group $2 ; \alpha=.05$, is the probability that $\theta(1) \leq \theta(2$

Table 3.7. Ethnic groups' difference on media types (Hausa vs. Ibo)

\begin{tabular}{ccccc}
\hline & Group 1: ( Hausa) & Group 2 :(lbo) & & \\
\hline Path(s) & $\theta^{(1)}$ & $\theta^{(2)}$ & Group Difference & P-Value \\
Online>NGO & 0.1186 & 0.1192 & 0.000600 & 0.516500 \\
Con >NGO & 0.0167 & 0.0162 & 0.000500 & $\mathbf{0 . 5 0 3 5 0 0}$ \\
\hline
\end{tabular}

Note: $\theta(1)$ and $\theta(2)$ are the parameter estimate (path coefficients) of Group 1 and Group 2; $\alpha=.05$, is the probability that $\theta(1) \leq \theta(2)$

Table 3.8. Ethnic groups' difference on media types (Yoruba vs. Ibo)

\begin{tabular}{ccccc}
\hline & Group 1: (Yoruba) & Group 2:(lbo) & & \\
\hline Path(s) & $\theta^{(1)}$ & $\theta^{(2)}$ & Group Difference & P-Value \\
Online media> NGO & 0.1193 & 0.1192 & 0.000100 & 0.497600 \\
Conventional media >NGO & 0.0164 & 0.0162 & $\mathbf{0 . 1 0 2 8 0 0}$ & $\mathbf{0 . 2 0 9 6 0 0}$ \\
\hline
\end{tabular}

Note: $\theta(1)$ and $\theta(2)$ are the parameter estimate (path coefficients) of Group 1 and Group 2; $\alpha=.05$, is the probability that $\theta(1) \leq \theta(2)$ 
Table 3.9. Ethnic groups' difference on media types (Yoruba vs. Hausa)

\begin{tabular}{lllll}
\hline & Group 1 : (Yoruba) & Group 2 : (Hausa) & & \\
\hline Path(s) & $\theta^{(1)}$ & $\theta^{(2)}$ & Group Difference & P-Value \\
Online media> NGO & 0.1193 & 0.1186 & 0.000700 & 0.491100 \\
Conventional media >NGO & 0.0164 & 0.118 & 0.000300 & 0.498300
\end{tabular}

Note: $\theta(1)$ and $\theta(2)$ are the parameter estimate (path coefficients) of Group 1 and Group $2 ; \alpha=.05$, is the probability that $\theta(1) \leq \theta(2)$,

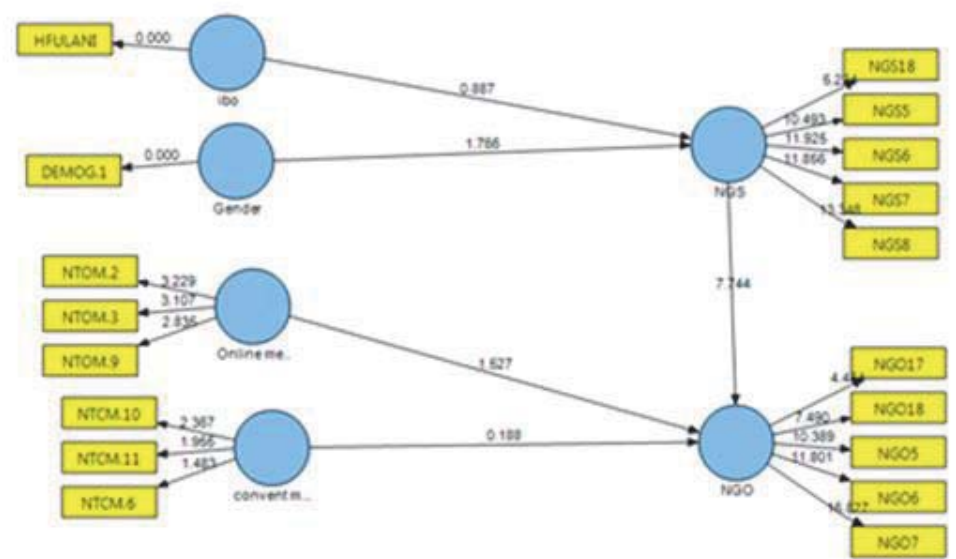

Figure 3.1 NGS vs. NGO (H/Fulani)

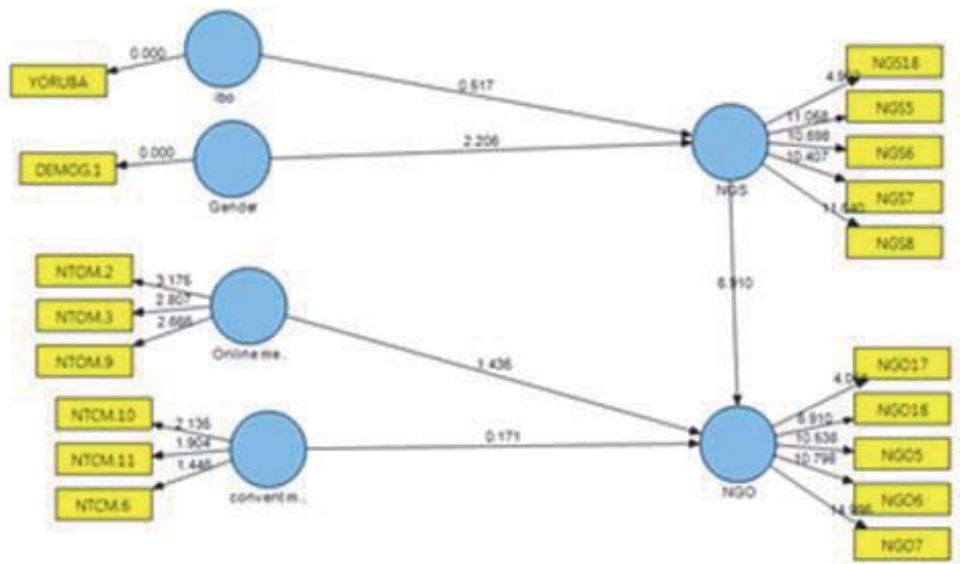

Figure 3.2 NGS vs. NGO (Yoruba)

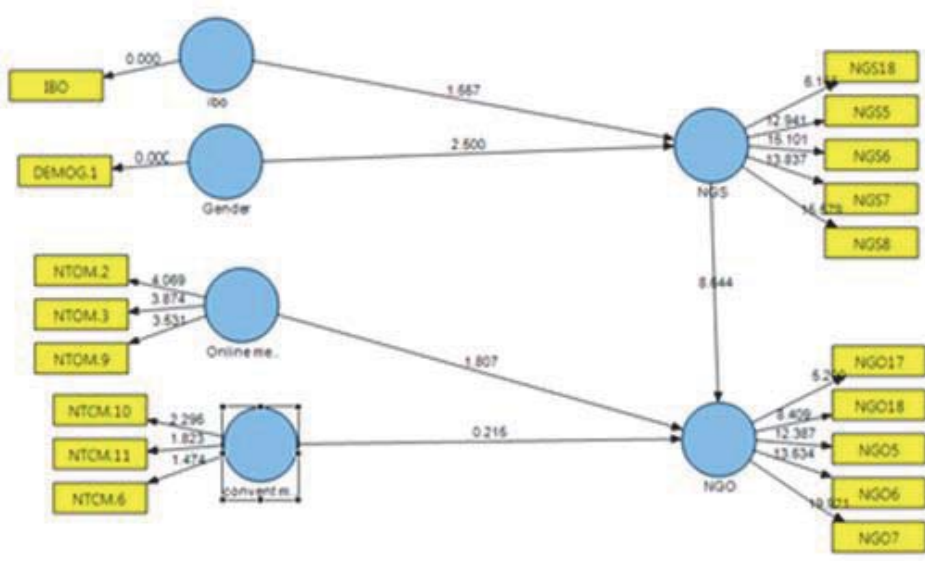

Figure 3.3 NGS vs. NGO (Ibo) 


\section{Conclusion}

The path relationship between ethnic identity and NGS shows that ethnic identity positively influences NGS. Although the size of the empirical t-value of ethnic identity (0.132) is less than the critical t- value of $t>1.65$ as suggested by Hair et al (2014), which indicates that ethnic identity does not significantly influence news gratifications sought, the result shows there is a direct relationship between ethnic identity and NGS. This conclusion is reinforced by the significant difference which is found to exist in the NGS of the three ethnic groups. These findings support findings of previous studies. Gerzduci and d'Haenens $(2010,2007)$ found significant difference in the news motives of ethnically diverse groups in Belgium. Albarran and Humphrey (1993) had also found significant difference in the TV news gratifications of Blacks and Hispanics in the United States

Even though there is a significant difference among the ethnic groups in their NGS, no significant difference is found among them in their usage of each of the online and conventional media for news. It does mean that the three ethnic groups use the same types of media to gratify different news needs. When this conclusion is juxtaposed with the finding that there is a positive correlation between the NGS and NGO of each of the ethnic groups, it could be further concluded that a particular media can give satisfaction to different needs of different users. The general implication of all these findings is that, consumers are disinterested about the medium. In other words, it is the motive that drives media choice for news consumption and not the media types (Dutta-Bergman, 2004). This conclusion is given a more concrete support by Dutta-Bergman's findings that in the United States, those who followed sports news in the new media complement that by also looking for sports news in the old media. Given all the findings and conclusions enumerated above, we will tend to align with the media scholars who opine that online and conventional media are playing complimentary role in news consumption. In other words, the online media has not displaced the traditional, conventional media as sources of news.

This study found gender to have stronger predictive relevance on news gratifications. The competitive power of ethnic identity as a predictor of news usage can be further explored vis-a-vis other demographic predictors like age, education level, socio-economic status which have been found to influence news usage in varying degrees

\section{References}

Althaus, S. L., \& Tewksbury, D. (2002). Agenda setting and the "new" news - patterns of issue importance among readers of the paper and online versions of the New York Times. Communication Research, 29(2), 180-20

Cotter, C. (2010). News talk: Investigating the language of journalism. Cambridge University Press.

Eccles, J. S. (2005). Studying gender and ethnic differences in participation in math, physical science, and information technology. New Directions for Child and Adolescent Development, 2005(110), 7-14.

Emenyeanu, B. N (1995). Media uses and Gratifications: A Review. African Media Review vol 9 no 3 90-112

Gandy, O. (1998). Communication and race: A structural perspective. London: Arnold.

Gezduci, H., \& d'Haenens, L. (2010). The quest for credibility and other motives for news consumption among ethnically diverse youths in Flanders: A culture-centered approach. Journal of Children and Media, 4(3), 331-349.

Ghorui, S. (2012). 'News use'-Informative or entertaining? An empirical study of college students' motives for using news (Doctoral dissertation, Orebro Universitty). Retrieved July 2013http://oru.divaportal.org/smash/get/diva2:532142/FULLTEXT01.

Hair Jr, J. F., Hult, G. T. M., Ringle, C., \& Sarstedt, M. (2014). A primer on partial least squares structural equation modeling (PLS-SEM). SAGE Publications, Incorporated.

Hall, A., Anten, T., \& Cakim, C. (1999). Perceived typicality: American television as seen by Mexicans, Turks, and Americans. Critical Studies in Mass Communication, 16(4), 436-455

Hamilton, J. (2004). All the news that's fit to sell: How the market transforms information into news. Princeton University Press.

John, I. A, Muhammad, A. Z, Pinto, A. D and Nkanta, C. A (rev) (2007). Gun violence in Nigeria: A focus on ethno-religious conflict in Kano. Journal of Public Health Policy, vol 26 No 4

Johnson-Cartee, K. S. (2005). News narratives and news framing: Constructing political reality. Rowman \& Littlefield.

Katz, E., Guveritch, M. \& Haas, H (1973). On the use of the media for important things. American Sociological Review 38 pp164-181

Livingstone, S., \& Markham, T. (2008). The contribution of media consumption to civic participation. British Journal of Sociology, 59(2), 351- 371

McCombs, M., Holbre, L.Kiousis, S \& Wanta, W (2011). The news and public opinion. Media effects on civic life. Polity Press. Cambridge. CB2, IUR, UK

Micheistein, E \& Boczkowski, P. J. (2010). Online news consumption research: An assessment of past works and an agenda for the future; New Media \& Society, vol 12, (2), 1085-1

Nguyen, A., \& Western, M. (2007). Socio-structural correlates of online news and information adoption/use: Implications for the digital divide. Journal of Sociology, 43(2), 167185

Osaghae, E. E and Suberu, R. T (2005). A history of identities, violence, and stability in Nigeria, CRISE working paper No. 6 
http://www.dfid.gov.uk/R4D/PDF/Outputs/Inequality/wp6.pdf. Retrieved October, 2012

Palmgreen, P., Weiner, L. A., \& Rayburn, J. D. (1980). Relations between gratifications sought and obtained: A study of television news. Communication Research, 7(2), 161-192.

Rubin, A. M., \& Rubin, R. C. (1985). Interface of personal and mediated communication: A research agenda, Critical studies in mass communication, 2(1), 36-53 in Ancu, M. and Cozma, R (2009) MySpace politics: Uses and gratifications of befriending candidates, journal of Broadcasting \& Electronic Media, 2009

Ruggiero, T. E. (2000). Uses and gratifications theory in the 21st century. Mass Communication \& Society, 3(1), 3-37

Salawu, B. (2010). Ethno-religious conflicts in Nigeria: Causal analysis and proposals for new management strategies European Journal of Social Sciences - Volume 13, Number 3345

Thapa, B. (2002). Information needs and search behaviors: A comparative study of ethnic groups in the Angeles and San Bernardino national forests, California Leisure Sciences, 24:89-107,

Wei, R. (2008). Motivations for using the mobile phone for mass communications and entertainment. Telematics and Informatics, 25(1), 36-46. 